\title{
Readers' use of source information in text comprehension
}

\author{
Jason L. G. Braasch • Jean-François Rouet • \\ Nicolas Vibert • M. Anne Britt
}

Published online: 16 November 2011

(C) Psychonomic Society, Inc. 2011

\begin{abstract}
In two experiments, we examined the role of discrepancy on readers' text processing of and memory for the sources of brief news reports. Each story included two assertions that were attributed to different sources. We manipulated whether the second assertion was either discrepant or consistent with the first assertion. On the basis of the discrepancy-induced source comprehension (DISC) assumption, we predicted that discrepant stories would promote deeper processing and better memory for the sources conveying the messages, as compared to consistent stories. As predicted, readers mentioned more sources in summaries of discrepant stories, recalled more sources, made more fixations, and displayed longer gaze times in source areas when reading discrepant than when reading consistent stories. In Experiment 2, we found enhanced memory for source-content links for discrepant stories even when intersentential connectors were absent, and regardless of the reading goals. Discussion was focused on discrepancies as one mechanism by which readers are prompted to
\end{abstract}

J. L. G. Braasch · J.-F. Rouet $\cdot$ N. Vibert

CNRS and University of Poitiers,

Poitiers, France

J. L. G. Braasch

University of Oslo,

Oslo, Norway

M. A. Britt

Northern Illinois University,

DeKalb, IL, USA

J. L. G. Braasch $(\bowtie)$

Department of Educational Research, University of Oslo,

P.O. Box 1092, Blindern,

N-0317 Oslo, Norway

e-mail: jason.braasch@uio.no encode source-content links more deeply, as a method of integrating disparate pieces of information into a coherent mental representation of a text.

Keywords Discrepancies · Eye movements · Memory · Sources $\cdot$ Text comprehension

There is an old saying that "there are two sides to every story." This saying describes the observation that, in everyday contexts, we are frequently presented with and must comprehend uncertain or tentative events, which have resulted in multiple interpretations. In newspaper reports, for example, a single event is often described (e.g., a fire in a building) that may be attributed to various reasons (sabotage vs. electrical malfunction), either within the same report or across several different ones. These kinds of discrepancies are notably different from simple errors in reporting; in fact, they are part and parcel of the state of affairs of the situation. In the present example, the cause of the fire may have been uncertain at the time that the newspapers were printed, investigation may be ongoing, and so on.

The present experiments were designed to give some clarity regarding the cognitive mechanisms that operate during the comprehension of discrepancies like these when they appear in texts, particularly when different sources are associated with the conflicting pieces of information (e.g., "The detective claims that the fire in the building was due to sabotage. However, a journalist asserts that the fire was caused by an electrical malfunction."). In the present work, we argue that comprehending discrepancies of this kind requires that readers attend to - and at times rememberwho said what. More colloquially, in the event that readers have accessed a discrepancy during reading, are they more 
likely to pay attention to and remember the "two sides to the story," and if so, why?

\section{Do readers regularly monitor their understandings of texts and notice when texts present conflicting statements?}

Text comprehension involves the incremental construction and updating of a mental representation of the situation described in the text (Kintsch, 1998). When reading continuous texts for comprehension, readers gradually develop a representation of a text as a whole through successive processing cycles, in part due to our limited working memory system (Goldman \& Varma, 1995; Goldman, Varma, \& Coté, 1996; Kintsch, 1988). Incoming information connects with information that is part of the developing representation (information that carries over in working memory) through coreference and other coherence-building processes (van den Broek, Risden, \& Husebye-Hartmann, 1995).

At times, however, comprehension requires that readers update their representations of the text in order to take into account new information that cannot be readily integrated with previous information (Albrecht \& O’Brien, 1993; Guéraud, Harmon, \& Peracchi, 2005; Myers \& O'Brien, 1998). Updating involves a range of processes that rely on reactivation of information previously stored in long-term memory (Goldman, Golden, \& van den Broek, 2007; van den Broek, Rapp, \& Kendeou, 2005; van den Broek, Young, Tzeng, \& Linderholm, 1999). A host of empirical studies have investigated the conditions affecting the reactivation of information from prior text during reading (Albrecht \& O'Brien, 1993; Cook, Halleran, \& O’Brien, 1998; Guéraud et al. 2005; Hakala \& O’Brien, 1995; McKoon \& Ratcliff, 1992; O’Brien, Rizzella, Albrecht, \& Halleran, 1998). Particularly salient for the present work is the fact that many empirical studies have used online processing measures to capture readers' responses to breaks in situational coherence - that is, discrepancies between two pieces of content information within a text (Albrecht \& O'Brien, 1993; Myers, O’Brien, Albrecht, \& Mason, 1994; O’Brien et al. 1998; Rapp, Gerrig, \& Prentice, 2001).

Many researchers have used the so-called inconsistency paradigm (e.g., Albrecht \& O’Brien, 1993) to investigate this issue. Within this paradigm, readers typically read narrative texts one sentence at a time. The texts first instantiate a protagonist (e.g., Mary) and assign a characteristic that is either consistent (e.g., fast food addict) or inconsistent (e.g., strict vegetarianism) with subsequent text. Filler sentences are added to ensure that the characteristic no longer resides in working memory. Processing, in terms of per-sentence reading time, is measured on target sentences that are or are not consistent with the backgrounded characteristic in long-term memory (e.g., "Mary ordered a cheeseburger and fries").

Studies using the inconsistency paradigm have consistently revealed that readers slow down on sentences introducing a discrepancy relative to passages that are consistent (Albrecht \& O'Brien, 1993; Gernsbacher, Goldsmith, \& Robertson, 1992; Guéraud et al. 2005; Hakala \& O'Brien, 1995; O'Brien \& Albrecht, 1992; O’Brien et al. 1998; Rapp et al. 2001; Rinck, Hähnel, \& Becker, 2001). Supplemental measures have suggested that increased reading times indicate, above and beyond merely noticing a discrepancy, readers' attempts to selectively retrieve and reprocess information from long-term memory that contradicted the target sentence. Strong evidence for this is that readers exhibit enhanced memory for the regions of texts conveying conflicting content, more than for other previously read sentences (Albrecht \& O’Brien, 1993; Baker \& Anderson, 1982; Hakala \& O'Brien, 1995; O'Brien \& Albrecht, 1992; O’Brien \& Myers, 1985; Tapiero \& Otero, 1999). Verbal protocol evidence supports the idea that readers frequently attempt to resolve the two contradictory statements. For example, in Blanc, Kendeou, van den Broek, and Brouillet (2008), readers verbalized inferences of causal relationships between two discrepant sentences. Similarly, others have demonstrated that readers may distort or "hedge" one or more aspects of the content statements to resolve the discrepancy (Black, Turner, \& Bower, 1979; Chinn \& Brewer, 1993, 1998; Hakala \& O'Brien, 1995; Mosenthal, 1979; Otero \& Kintsch, 1992).

Recent efforts have capitalized on the affordances of eye movement methodologies to better understand the cognitive processes surrounding readers' resolution attempts during unrestricted reading (Blanchard \& Iran-Nejad, 1987; Cook \& Myers, 2004; Daneman, Lennertz, \& Hannon, 2007; Rayner, Chace, Slattery, \& Ashby, 2006; Rinck, Gámez, Díaz, \& de Vega, 2003). These studies demonstrated that, when readers come across a statement containing information that is discrepant with previously read information, they return to the discrepant information to more "deeply" reprocess its content. For example, Rinck et al. (2003) showed that readers made more regressive eye movements back to previously read information that contradicted the focal sentence, and also made longer fixations in response to that portion of the text. Eye movement measures such as these are thought to indicate repair processes (Frazier \& Rayner, 1982; Hyönä, Lorch, \& Rinck, 2003; Rayner, 1998; Vauras, Hyönä, \& Niemi, 1992; Wiley \& Rayner, 2000), which one might expect readers to undertake in service of attempting to resolve a discrepancy. To summarize, readers seem to selectively reprocess the two contradictory propositions in an attempt to establish coherence. 


\section{How successfully do readers resolve breaks in situational coherence?}

The studies cited thus far, however, do not speak to readers' success (or lack thereof) in "updating" their representations. A great deal of research has been conducted to investigate this very issue. For example, some researchers have incorporated additional manipulations into the inconsistency paradigm, including adding qualifications with and without reasons (e.g., "Mary doesn't stick to her diet when dining out"), shifting of time frames (e.g., "Mary is not a vegetarian anymore"), and negations and refutations with or without substantial explanations (e.g., "Mary was never a vegetarian") (Guéraud et al. 2005; O’Brien et al. 1998; Rapp \& Kendeou, 2007, 2009; Zwaan \& Madden, 2004). In response to these reading situations, the initially represented information will often display a continued influence on comprehension-regardless of whether that portion of the reader's representation was deemed by the text as operational or not.

Similar findings have arisen in a related literature focusing on the processing and understanding of corrections to misinformation (Johnson \& Seifert, 1994, 1998, 1999; Seifert, 2002; van Oostendorp \& Bonebakker, 1999; Wilkes \& Leatherbarrow, 1988). The misinformation correction paradigm involves the reading of expository accounts of events (e.g., causes of a fire) as a series of breaking news briefs. A causal account is instantiated (e.g., a storage closet contained oil paint). Additional sentences provide further details of the account (e.g., there was thick smoke reported, no fatalities, etc.). Later, a correction is provided regarding the previous misinformation (e.g., the closet reportedly holding oil paint was actually empty). The extent to which readers remain influenced by the initial misinformation is assessed using recall and inference-level items.

In response to this paradigm, readers' event recalls typically align with the corrected account (Seifert, 2002; van Oostendorp \& Bonebakker, 1999; Wilkes \& Leatherbarrow, 1988). When responding to inferential questions, however, readers invariably draw upon incorrect, outdated information (H.M. Johnson \& Seifert, 1994, 1999; Seifert, 2002; van Oostendorp, 2002; van Oostendorp \& Bonebakker, 1999; Wilkes \& Leatherbarrow, 1988). For example, comprehenders constructed inferences on the basis of misinformation both before and after a correction, regardless of whether the correction was proximal or distal (H.M. Johnson \& Seifert, 1994). Moreover, speeded verification tasks have demonstrated that the correction and misinformation are verified equally quickly throughout comprehension, and more quickly than a filler control condition (H.M. Johnson \& Seifert, 1998).

Taken together, these findings suggest that, although readers can recognize a need for resolution surrounding breaks in situational coherence, they are not always successful in doing so. When pairing reading behaviors with readers' recall and inference-level performance, the increased recall for discrepant information suggests that readers recognize the importance of reestablishing coherence and apply various strategies for doing so. However, the continued influence of the currently viable and the outdated information on inference-level performance additionally suggests that mental representations stemming from these paradigms are rather fragmented and incoherent. For example, groups receiving misinformation correction often provide completely contradictory responses across inference-level questions, and at times within the same question (Seifert, 2002; van Oostendorp, 2002; Wilkes \& Leatherbarrow, 1988).

Thus, when presented with discrepant information, readers appear to store some components of the newer and the outdated information and to use both types of information during comprehension (H.M. Johnson \& Seifert, 1994, 1999; Seifert, 2002; Tapiero \& Otero, 1999; van Oostendorp \& Bonebakker, 1999). The reliance on old information may be due to readers' reluctance or difficulty in reconsidering their mental model of the situation (i.e., the set of inferences and connections that were made on the basis of the old information). However, the effect may be particularly strong when the text does not provide any real mechanisms to resolve the contradiction.

\section{Integration of sources and content}

In natural discourse situations, contradictions often arise when different sources make claims about a topic (as described in the fire example above). In these discourse situations, textual inconsistencies are not anomalous, but instead result from the uncertain, tentative, or conflicting nature of the claims about the situation. Accordingly, the indexing of content information to the respective sources may provide an alternative mechanism for structuring one's mental representation of the text.

The source-monitoring framework (SMF; M.K. Johnson, Hashtroudi, \& Lindsay, 1993) is a theory of how people make decisions about the sources of their memories after they are done reading on the basis of the features of their memory representations. Some examples include being able to accurately determine whether a specific fact was acquired from viewing a picture or reading a text, the color of the paper the fact was presented on, the gender of the voice that presented it, or even whether it was experienced or imagined. According to the SMF, certain contextual information about the episode is encoded. Later, when prompted to determine the source of that information, people can rely on a reactivation of the context and an evaluation of the cognitive processes that occurred during encoding. Accordingly, the 
SMF functions as a framework of memory retrieval and decision making. The SMF does not, however, propose that people specifically mark events by their sources during encoding. Instead, source information is an inference made as needed on the basis of the memory record. In the words of Johnson, Hashtroudi, and Lindsay, "a central claim of the source-monitoring approach is that people do not typically directly retrieve an abstract tag or label that specifies a memory's source, rather, activated memory records are evaluated and attributed to particular sources through decision processes performed during remembering" (p.3).

Nevertheless, previous research has also demonstrated that at times, readers do strategically attend to and evaluate source information during encoding (Anmarkrud, Bråten, \& Strømsø, 2011; Goldman, Braasch, Wiley, Gepstein, Brodowinska and Graesser 2004; Rouet, Britt, Caroux, Nivet, \& Le Bigot, 2009; Wineburg, 1991). This is the case, for instance, when readers are confronted with texts that violate their prior beliefs or expectations or when faced with conflicting accounts of a situation. We propose that readers allocate increased attention to the information sources that accompany or are cited in texts in an attempt to understand conflicting accounts of a situation. We refer to this assumption as the discrepancy-induced source comprehension or D-ISC assumption. D-ISC states that perceived textual discrepancies or breaks in situational coherence are one potential mechanism by which readers are prompted to attend more strategically to and evaluate source information during encoding. This "deeper" encoding of the connections between sources and their respective content statements results in a greater likelihood that readers will construct source-content links into their mental representation of the text(s) (see the source-to-content links in Fig. 1: "According to source A...," "According to source B..."). We further explicate our processing assumptions below.
In alignment with a class of models that serve to describe the psychological processes underlying text comprehension (Goldman, Varma, \& Coté, 1996; Kintsch, 1988, 1998; Myers \& O'Brien, 1998; van den Broek et al. 1999), we assume that readers proceed through texts in incremental ways, in part due to their limited working memory systems. Each increment, or processing cycle, corresponds to a proposition or sentence. Propositions that are coactivated on the same cycle may be connected to one another. These propositions include those that were activated during previous cycles if those remain at sufficiently high levels of activation. A representation of the text as a whole develops through successive processing cycles as incoming information connects with information that is part of the developing representation (Goldman et al. 2007; Kintsch, 1988; van den Broek et al. 2005; van den Broek et al. 1999).

In the case of relatively brief texts - such as the fire example above - the content assertion activated from the first sentence (the fire in the building was due to sabotage) should remain at sufficiently high levels when the second discrepant content assertion (the fire was caused by an electrical malfunction) is the text input. Coactivation in working memory, thus, may serve as a condition by which readers are able to recognize the presence of a break in situational coherence (see van den Broek \& Kendeou, 2008, for a similar argument). The D-ISC assumption entails the specific claim that, when the source of the discrepant information is present in the text (e.g., "the detective claims" and "the journalist asserts"), readers will return to and more deeply encode this information. This deeper encoding would, in turn, result in a greater presence of source-content links in the readers' memory representations of texts relative to texts that do not involve discrepancies.
Fig. 1 Theoretical representation of discrepancyinduced source comprehension. $\operatorname{rs}(\mathrm{A} / \mathrm{B})=$ representation of source $\mathrm{A} / \mathrm{B} ; \mathrm{rc}(\mathrm{A} / \mathrm{B})=$ representation of content $\mathrm{A} / \mathrm{B}$

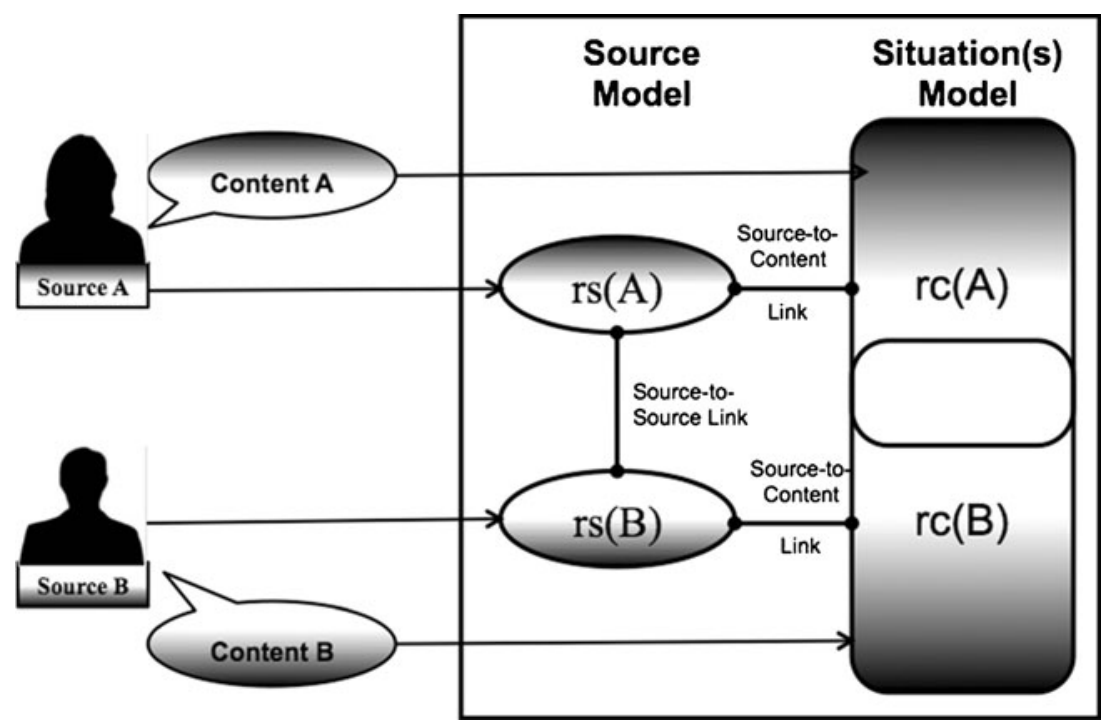


In the case of extended discourse, the reader may process several sentences, paragraphs, or even texts between discrepant content assertions. Similar in operation to associative or resonance processes specified in the construction-integration and resonance models of text comprehension (Gerrig \& O'Brien, 2005; Kintsch, 1988, 1998; Myers \& O’Brien, 1998; O’Brien \& Myers, 1999), we assume that, at the point at which the second content assertion acts as the text input, passive, automatic, and memory-based activation spreads, and related information reenters working memory from long-term memory. In the fire example, the content assertion that the fire in the building was due to sabotage would reenter working memory after reading that the fire was caused by an electrical malfunction, likely due to a high degree of content overlap. If so, one could expect that, even in the case of extended discourse, blatant discrepancies might still instigate readers to go back to and reprocess source information in service of constructing source-content links into their mental representations of the texts.

In summary, the D-ISC assumption states that when reading discrepant information, readers will pay more attention to the sources of information (i.e., who says what) and that they will be more likely to integrate sources in their memory representations. The D-ISC assumption, if verified, would add to a theory of discourse comprehension by considering pieces of textual discourse in which information is provided by multiple and sometimes conflicting sources. In contrast, previous theories, such as the construction-integration theory (Kintsch, 1998), have not made any particular assumption as to whether, when, or why information sources may become part of the reader's memory representation of the text.

Since D-ISC is a novel assumption, there is, as of yet, no empirical support for its processing and representational claims. Initial support for at least the representational claim, however, can be found in research on multiple-document comprehension - specifically, empirical work referencing the documents' model framework (Britt, Perfetti, Sandak, \& Rouet, 1999; Perfetti, Rouet, \& Britt, 1999; Rouet, 2006). We note that, although the presence of discrepancies per se has been manipulated in none of these experiments, the models are similar to ours in the sense that they signify comprehension contexts in which multiple conflicting accounts are presented. Their cases are different, however, because the discrepancies are across separate, clearly demarcated documents that are typically fairly long in length. Although few in number, the studies based on such models appear to provide support for the claims put forth by the D-ISC assumption. For example, Britt et al. (1999) demonstrated that undergraduates could name the sources of a given piece of content information at better than chance levels after comprehending multiple, conflicting historical texts. Similarly, Strømsø, Bråten, and Britt (2010) provided evidence for a significant relationship between "deeper" comprehension - in terms of postreading performance on assessments of the connectedness of readers' multiple-document representations - and readers' memory for the information sources. Recent work by Stadtler, Scharrer, Brummenhenrich and Bromme (2011) demonstrated that readers were more likely to explicitly mention a conflict between documents that were purportedly authored by expert sources, and that they predominantly attributed conflicts to different sources above all other possible attribution dimensions (e.g., self-attributions, attributions to the Internet as a medium). All told, these relationships suggest that discrepancies across the contents of documents triggered a greater consideration of the source features of documents, as evidenced by reading "products" (i.e., indications of postreading understandings of multiple documents).

These findings stand in opposition to experiments conducted with reference to the SMF framework. For instance, Kim and Millis (2006) found that the more a reader integrates information from the text, the less he or she can attend to and comprehend source information. However, in their experiment, the sources were neither semantic nor distinctive. In fact, Kim and Millis used the same two arbitrary sources (fictitious Internet news agencies) for all of their experimental items. In contrast, experiments providing distinctive semantic sources for each document in a set have suggested that better integration of information from multiple documents corresponds with greater memory for source information (e.g., Strømsø et al. 2010). Thus, in comprehension contexts where multiple conflicting messages are presented (in this case, as separate documents), conflicting claims appear to prompt a "deeper" encoding of and better memory for the source-content links.

While these empirical examples can be interpreted as supporting the processing and representational assumptions of D-ISC, no experiments have provided direct evidence to date. Do discrepancies between multiple messages impact readers' moment-by-moment processing of a text, particularly in terms of the encoding efforts they allocate to source information? Do discrepancies also result in an increased presence of source-content links in readers' memory representations of a text? These questions were the primary foci in the present research.

\section{The present research}

Thus, the present research was conducted to directly test DISC's processing and memory representation assumptions with respect to comprehension of natural discourse - that is, 
brief news articles that presented different sources making claims on various topics. In Experiment 1, we assessed the processing assumption by recording the eye movements that readers produced while reading consistent and discrepant versions of the news stories. We additionally tested readers' memory for the source-to-content links after some delay. On the basis of the D-ISC assumption, we predicted that, after accessing a break in situational coherence (i.e., the discrepant content information), readers should allocate more processing resources (in terms of fixations and gaze times) to source areas of the text, as compared to their reading patterns for stories that did not present breaks in situational coherence (i.e., the consistent story versions). Regarding memory for sources, it was expected that readers would display a greater recall of source-content links from discrepant than from consistent stories (even when controlling for the to-be-recalled sentences). Experiment 2 was conducted to rule out an alternative explanation for the Experiment 1 findings and to generalize the findings to additional reading goals.

\section{Experiment 1}

\section{Method}

\section{Participants}

A group of 25 French undergraduate students enrolled in a psychology program participated in this experiment. All were native French speakers and had normal or correctedto-normal vision. The data for 1 participant were not analyzed because of unreliable, low-quality eye movement recordings. A final sample size of 24 participants had yielded sufficient power levels in previous research examining eye movements in response to consistent versus discrepant versions of texts (Cook \& Myers, 2004; Rayner et al. 2006; Stewart, Pickering, \& Sturt, 2004). The average age in our experiment was 21.5 years $(S D=3.0)$, and $75 \%$ of the participants were female. All participants were compensated with $1 \mathrm{~h}$ of course credit for their participation.

\section{Materials}

Texts A total of 16 critical stories were created that described news events (topics extracted from the Internet, which included science, society, and the economy, to name a few). See Example 1 for an English translation of one of the stories that were presented in French. Structurally, each story comprised two sentences, each of which was composed of a source and a content statement, along with a connector that related the two sentences.
Example 1 According to the art critic, the public (booed/ cheered) the new show of the Paris opera. (Indeed/On the contrary), the lighting technician claims that half the public went back home before the intermission.

The primary manipulation involved consistent and discrepant versions of each story. In the consistent story condition, the two sentences presented the same "message" within the content statements (e.g., booed, went back home before the intermission). In the discrepant story condition, the two sentences presented oppositional messages within the content statements (cheered, went back home before the intermission). Thus, in all instantiations of the manipulation, the content of the first sentence was modified to either concur with or oppose the content of the second sentence. The connectors were also modified to convey that the two sentences were similar (Indeed) or adversative (On the contrary). It is important to note that the content statements within the second sentences and both sources were held constant across text versions. In addition to the critical stories, we wrote 6 additional two-sentence stories with a different rhetorical structure. These filler stories did not include contrasting perspectives. The 16 critical ( 8 discrepant and 8 consistent) and 6 filler stories were assembled into a story pool, and all participants received a random ordering of the 22 stories.

We conducted a pilot study to assess students' perceptions of the consistency of the critical stories. A group of 16 undergraduate students participated for course credit and were not involved in the main study. They were asked to read the stories and to rate whether the story "contained a disagreement or a contradiction" on a scale from 0 (no contradiction at all) to 10 (very strong contradiction). The average ratings for the consistent and discrepant versions were $0.9(S D=0.8)$ and 8.8 $(S D=1.0)$, respectively. Participants rarely gave a rating that was on the "wrong" side of the scale (i.e., higher than 5 for consistent versions or lower than 5 for discrepant versions). In fact, this occurred for only 13 of the 256 ratings $(5.1 \%)$. These unexpected ratings were distributed across 11 of the 16 stories and 8 out of the 16 students. We speculate that these ratings may have been due to students' misreading or temporarily "zoning out." In all other cases, the students were able to clearly identify the status of each story.

Cued recall test Memory for the source-content links was assessed using 16 statements taken from the second sentences of the critical stories (i.e., the source-content pair that was unaffected by the manipulation; see Example 2).

Example 2 claims that half the public went back home before the intermission. 


\section{Apparatus}

Eye movements were recorded using a TOBII 1750 eyetracker, which displayed the stimuli on a 17 -in. monitor using a screen resolution of $768 \times 1,024$ pixels. The eyetracking system was interfaced with an IBM-compatible laptop, which controlled the operation of the eyetracker and recorded the time spent on each slide and all eye movement data via dedicated TOBII software (ClearView 2.7.1). The eyetracker provided gaze positions at a sampling frequency of $50 \mathrm{~Hz}$ with a precision of $0.5^{\circ}$ of visual angle (approximately 15 pixels at a viewing distance of $60 \mathrm{~cm}$ ). Fixations were defined as any period in which the participant's gaze rested for $60 \mathrm{~ms}$ (i.e., three successive gaze points sampled at $50 \mathrm{~Hz}$ ) or more within a 20-pixel (about $0.7^{\circ}$ ) diameter area. Texts were presented in doublespaced format, and all letters were in lowercase (except for the first letters of sentences and proper nouns) 30-point Calibri font (i.e., approximately $1 \mathrm{~cm}$ in letter height, with an approximately $1.7-\mathrm{cm}$ interval between the lines). The viewing distance was approximately $60 \mathrm{~cm}$ for each participant.

\section{Procedure}

All participants were tested individually in a small experimental room. They were first informed that they would read information from a computer screen and, when doing so, their eye movements would be recorded. After consent was provided, the experimenter conducted a standard calibration procedure with the participant. This procedure remained consistent across all participants and was performed to ensure accurate eye fixations.

Participants were then instructed to imagine that they had just been hired as an editor at a news agency on the Internet. Their task was to silently read a series of twosentence stories and, after each story, to provide a verbal summary. The summaries were to be a single sentencethat is, shorter than the original story - but should still maintain the essential information. The instructions also specified that the readers should try to remember the story, because they would be asked to recall information from the story later in the experimental session. To ensure that participants understood the instructions, we provided a brief training session using two stories on topics unrelated to the core text set. Participants were then allowed to complete the read-and-summarize task at their own pace.

For each text, there were two screens: a reading and a summary screen. On the reading screen, participants were required to silently read the text and prepare their summary. At the bottom of each reading screen was written "Press the SPACE BAR when you are ready to give your summary." The summary screen presented a duplicate of the reading screen that participants could view while uttering their summary. Here, "Press the SPACE BAR when you are ready to continue" was displayed at the bottom. Thus, the two-screen sequence afforded us the opportunity to separate eye movement recordings for the silent reading phase and the verbal summary phase. To reduce reading fatigue, participants completed an intermediate, nonverbal filler task, which was provided between the first and second blocks of 11 stories. The filler task consisted of four items taken from the Minnesota Paper Board Form test (Likert \& Quasha, 1995). Verbal summaries were recorded for later transcription using a Tascam DR-1 portable digital recorder.

After completing the read-and-summarize task, participants were provided with a 34-item vocabulary task in which they had to find a synonym to a common word among a list of six words. This task served as a distractor task to reduce any cued recall effects associated with rehearsal and/or short-term memory. The participants were allotted $10 \mathrm{~min}$ to complete the vocabulary task. Immediately following this phase of the experimental session, participants were provided with the 16-item cued recall test described above. Their instructions were to recall the source associated with each statement by writing a response in the blank provided. Upon completion of the cued recall test, participants were debriefed and dismissed.

\section{Scoring and dependent measures}

Eye movements Five areas of interest (AOIs) were specified for each story. Separate AOIs were drawn around each of the two sources, each of the two content statements, and the connector (see Example 3). Moreover, the D-ISC predictions were for deeper reprocessing of the sources once a break in situational coherence was accessed (i.e., after having accessed the final content statement in the second sentence). As such, we established a "cut point" to separate first reading of the text and second reading or "reprocessing" of previously read text. The cut point was defined by the first regression out of the second content statement AOI (see the underlined portion of Example 3) into any previously read AOI. Thus, all fixations preceding the cut point were considered first reading, and all fixations following the cut point were considered second reading. We focused our analysis on two eye movement indices, the number of fixations and the total gaze times, within each of the AOIs.

Example 3 | According to the art critic, the public cheered the new show of the Paris opera.| On the contrary,| the lighting technician claims that half the public went back home before the intermission. 
Summaries We used the source citation scoring procedure of Rouet, Britt, Caroux, Nivet, and Le Bigot (2009). That is, each summary was scored for the presence or absence of citation of at least one of the sources. References to sources were counted if they were complete ("art critic," "lighting technician"), partial ("critic," "technician"), paraphrased (e.g., "art evaluator," "lighting staff”), or more general (e.g., "two sources disagree," "some feel"). Two raters practiced on two protocols and independently scored one-fifth of the remaining protocols. Agreement was acceptable (92\% agreement, Cohen's kappa of .84), and intercoder disagreements were resolved through discussion. One coder scored the remaining summary responses.

Cued recall Two independent coders scored the accuracy of $20 \%$ of the cued recall responses blind to text conditions. References to sources were counted if they were complete, partial, or paraphrased. Agreement was 100\% (Cohen's kappa of 1.00). One coder scored the remaining recall responses.

\section{Results}

Source citation in reader-generated summaries

Repeated measures $t$ tests using story consistency (discrepant or consistent) as the within-participants variable (all $t_{1}$ analyses used participants as a random source of variance, and all $t_{2}$ analyses used items as a random source of variance) demonstrated that source citation varied as a function of the consistency of the news stories, $t_{1}(23)=$ 5.94, $p<.001$, Cohen's $d=1.13 ; t_{2}(15)=5.03, p<.001$, Cohen's $d=1.95$. When readers generated summaries for discrepant stories, they cited source information more often $\left(M=0.69, S D_{1}=0.28\right)$ than when they generated summaries for consistent stories $\left(M=0.35, S D_{1}=0.32\right) .{ }^{1}$ An inspection of the means indicated that readers were approximately twice as likely to cite sources within their gist summaries of discrepant as compared to consistent news stories.

\section{Cued-recall test performance}

Repeated measures $t$ tests using story consistency (discrepant or consistent) as a within-participants variable produced significant memory differences for the source-content links, $t_{1}(23)=3.12, p<.01$, Cohen's $d=0.73 ; t_{2}(15)=3.31, p<$

\footnotetext{
${ }^{1}$ Only standard deviations associated with the analyses using participants as a random source of variance are reported here, for the sake of concision.
}

.01 , Cohen's $d=0.73$. As predicted, participants recalled more sources from discrepant $\left(M=4.88, S D_{1}=2.15\right)$ than from consistent $\left(M=3.38, S D_{1}=1.97\right)$ stories. The large effect sizes suggest a rather robust source memory advantage associated with discrepant stories (Cohen, 1988).

Analysis of eye movements

Numbers of fixations Due to the large number of statistical comparisons associated with the eye movement data, Bonferroni corrections were used. Numbers of firstreading fixations were submitted to five repeated measures $t$ tests, one corresponding to each of the focal AOIs. Table 1 displays the means and standard deviations associated with the participants analyses. The results indicated that no differences across the story manipulation achieved acceptable levels of statistical significance $\left[t_{1} \mathrm{~s}(23)<2.07\right.$, n.s.; $t_{2} \mathrm{~s}$ $(15)<2.00$, n.s.].

The means and standard deviations associated with the second-reading analyses are also displayed in Table 1. From visually inspecting the mean numbers of fixations, it is apparent that readers spent a fair amount of their processing effort on reprocessing the texts (i.e., second readings involved about two-thirds of their overall fixations). The results specifically indicated that readers made significantly more fixations on the first $\left[t_{1}(23)=4.62, p<.01\right.$, Cohen's $d=0.67]$ as well as the second $\left[t_{1}(23)=3.01, p<\right.$ .01 , Cohen's $d=0.36$ ] sources when reading discrepant relative to consistent stories. All other effects across consistency conditions did not reach acceptable levels of significance, $t_{1} \mathrm{~s}(23)<1.82$, n.s. The same general pattern was found when we used items as the random source of variance; however, the $t_{2}$ effect for the second source did not approach an acceptable level of statistical significance in the items analysis. That is, readers tended to make more fixations on the first source $\left[t_{2}(15)=2.75, p=.01\right.$, Cohen's $d=0.86]$ while reading discrepant stories as compared to consistent ones, but the effect was much weaker and nonsignificant for the second source $\left[t_{2}(15)=\right.$ $1.38, p=.19$, Cohen's $d=0.57]$. All other effects across consistency conditions did not reach acceptable levels of significance, $t_{2} \mathrm{~s}(15)<1.01$, n.s.

Gaze times Average first-reading gaze times were submitted to five repeated measures $t$ tests, one corresponding to each of the focal AOIs. Table 2 displays the means and standard deviations associated with the participants analyses. None of the $t_{1}$ or $t_{2}$ analyses resulted in significant differences during first-reading times, $\left[t_{1} \mathrm{~s}(23)<1\right.$ and $t_{2} \mathrm{~s}$ $(15)<1$, all n.s.]. However, as in the fixation frequency data, readers did spend more time rereading within source AOIs for discrepant as compared to consistent stories. This effect was present for both the first $\left[t_{1}(23)=5.00, p<.001\right.$, 
Table 1 Experiment 1: Mean numbers of fixations readers made during first and second readings, using participants as the source of random variance

Figures in bold were significantly different across the discrepant and consistent stories.

\begin{tabular}{|c|c|c|c|c|}
\hline & \multicolumn{2}{|l|}{ First Reading } & \multicolumn{2}{|c|}{ Second Reading } \\
\hline & $\begin{array}{l}\text { Discrepant } \\
\text { Mean }(S D)\end{array}$ & $\begin{array}{l}\text { Consistent } \\
\text { Mean }(S D)\end{array}$ & $\begin{array}{l}\text { Discrepant } \\
\text { Mean }(S D)\end{array}$ & $\begin{array}{l}\text { Consistent } \\
\text { Mean }(S D)\end{array}$ \\
\hline Source 1 & $8.61(3.32)$ & $7.82(2.62)$ & $18.38(9.04)$ & $13.28(5.92)$ \\
\hline Content 1 & $15.01(5.04)$ & $15.29(5.30)$ & $43.49(23.47)$ & $39.46(23.68)$ \\
\hline Connector & $2.01(0.62)$ & $1.81(1.01)$ & $5.10(2.60)$ & $4.33(2.33)$ \\
\hline Source 2 & $4.49(1.51)$ & $4.70(1.47)$ & $14.43(7.73)$ & 11.60 (7.92) \\
\hline Content 2 & $9.39(2.84)$ & $9.12(1.76)$ & $20.64(8.90)$ & $23.22(16.54)$ \\
\hline
\end{tabular}

Cohen's $d=0.74 ; t_{2}(15)=3.92, p<.01$, Cohen's $\left.d=1.15\right]$ and second $\left[t_{1}(23)=2.93, p<.01\right.$, Cohen's $d=0.35$; $t_{2}(15)=1.67, p<.12$, Cohen's $\left.d=0.66\right]$ sources. Again, the Source 2 effect did not approach acceptable levels of statistical significance when using items as the source of random variance. It is noteworthy, however, that both effect sizes were moderate to large for the behavioral data, which suggests that the lack of statistical significance may have been due to the reduced degrees of freedom. All other effects across consistency conditions did not reach acceptable levels of significance, $\left[t_{1} \mathrm{~s}(23)<1.55, t_{2} \mathrm{~s}(15)<1.08\right.$, all n.s.].

\section{Discussion}

Experiment 1 produced three findings. First, readers more frequently used source information when summarizing news reports that involved discrepant assertions, as compared to news reports in which two sources were in agreement. Because text summarization is considered one index of readers' gist representations of text information (van den Broek \& Trabasso, 1986), these findings suggest that sources played a role in the organization of readers' representations of the events expressed in the news stories. Second, readers displayed better memory for source information if the information was presented in conjunction with discrepant assertions, as compared to cases in which the sources agreed. This effect qualifies previous research that has demonstrated readers' enhanced memory for regions of texts conveying conflicting content information (Albrecht \& O’Brien, 1993; Hakala \& O’Brien, 1995; O’Brien \& Myers, 1985; Tapiero \& Otero, 1999). When texts imply that discrepant assertions are associated with two distinct and meaningful sources, readers instead display enhanced memory for source-content links. This was, again, relative to their memory for texts that implied sources stating consistent assertions. In the present work, we additionally controlled for the saliency of the content information by specifically testing readers' source-content memory links for the second sentences (i.e., those that were held constant across the experimental manipulation of story consistency). Thus, the recall memory data suggest that, when afforded the opportunity, readers rely on sources as a mechanism for integrating information in the news stories, specifically when coherence-based integration is unclear or impossible.

Third, with respect to the eye movement findings, the data suggest that readers noticed when news stories presented discrepant assertions and selectively reprocessed the source information during reading - that is to say, readers returned to information sources to fixate on them more often and for longer periods of time, particularly in the event that the news stories presented a break in situational coherence. Whereas previous research demonstrated that readers expend increased processing efforts focused on global inconsistency resolution-that is, on contradictory relative to consistent content statements
Table 2 Experiment 1: Mean reader gaze times during first and second readings (in milliseconds), using participants as the source of random variance

Figures in bold were significantly different across the discrepant and consistent stories.

\begin{tabular}{|c|c|c|c|c|}
\hline & \multicolumn{2}{|l|}{ First Reading } & \multicolumn{2}{|l|}{ Second Reading } \\
\hline & $\begin{array}{l}\text { Discrepant } \\
\text { Mean }(S D)\end{array}$ & $\begin{array}{l}\text { Consistent } \\
\text { Mean }(S D)\end{array}$ & $\begin{array}{l}\text { Discrepant } \\
\text { Mean }(S D)\end{array}$ & $\begin{array}{l}\text { Consistent } \\
\text { Mean }(S D)\end{array}$ \\
\hline Source 1 & $1,801.61(759.65)$ & $1,737.57(734.45)$ & $4,334.86(2,288.82)$ & $2,894.94(1,490.74)$ \\
\hline Content 1 & $3,071.90(1,065.78)$ & $3,214.80(1,287.67)$ & $9,751.30(5,870.70)$ & $8,726.14(5,407.56)$ \\
\hline Connector & 397.78 (167.68) & $375.62(196.65)$ & $1,115.17(637.51)$ & $1,001.45(617.61)$ \\
\hline Source 2 & $925.51(463.94)$ & $921.72(306.65)$ & $3,107.96(1866.81)$ & $2,467.69(1,812.56)$ \\
\hline Content 2 & $1,892.70(779.19)$ & $1,849.10(726.16)$ & $4,273.45(2,300.48)$ & $4,845.65(3,852.27)$ \\
\hline
\end{tabular}


(Rayner et al. 2006; Rinck et al. 2003) - the Experiment 1 findings suggest that, when texts afford readers opportunities to represent the textual assertions in terms of their respective sources, readers rely on these sources as mechanisms for integrating information, and accordingly expend more processing effort in service of integration.

Although the results suggest that the presence of a break in situational coherence, as induced by discrepant content assertions, resulted in deeper encoding and better memory for source-content links, Experiment 1 had several limitations. First, connectors were incorporated so that readers experienced the information contained within the two sentences as connected discourse. One could argue that the presence of linguistic markings of the relations between the sentences as consistent or discrepant might have influenced moment-by-moment processing and, ultimately, the "products" of reading (in this case, readers' memory for source-content links). A great deal of research has corroborated that connectors can serve as signals for, and thus facilitate, intersentential integrative processing, which also affects the text representations that result from reading (Caron, Micko, \& Thüring, 1988; Millis \& Just, 1994; Noordman \& Vonk, 1997; Sanders \& Noordman, 2000). In the most relevant example, Caron et al. demonstrated that two sentences connected by words indicating a discrepancy ("but") and sentences connected by words indicating a consistency ("and") were similarly recalled, but discrepant connectors did elicit more elaborative processing. This was evidenced by the larger number of inferential errors generated to connect the two sentences in the discrepantconnector condition. With respect to our findings, the presence of discrepant connectors might have differentially influenced readers' elaborative processing of the information within the sentence pairs, potentially accounting for the enhanced memory for source-content links associated with the discrepant news stories.

Regarding a second limitation of Experiment 1, one could argue that the construction of source-content links was influenced by the fact that readers were tasked to summarize the texts. Thus, in Experiment 2, we tested the generalizability of the effect across a wider range of tasks that varied in the extent to which they required integration.

\section{Experiment 2}

\section{Rationale}

Experiment 2 was conducted to provide additional support for the D-ISC assumption. As in Experiment 1, we investigated whether readers would display better recall of source-content links from news stories with discrepant assertions than from stories that were consistent. In response to the Experiment 1 limitations, there were two particular goals for Experiment 2. One goal was to exclude the explanation that the connectors were the locus of the Experiment 1 effects. Ruling out this alternative explanation would, in turn, further support our assumption: The presence of discrepant assertions (as one example of a break in situational coherence) instigates the construction of source-content links in long-term memory. As such, we removed the potentially influential consistent and discrepant connectors in Experiment 2. Therefore, we predicted that discrepant assertions would still result in a greater presence of sources in students' generated gist representation statements, as well as greater memory for sourcecontent links after reading.

A second goal was to test whether or not the enhanced source memory effect associated with discrepant stories would generalize to additional reading goals. As such, a between-participants task manipulation required that readers generate a one-sentence summary, a one-sentence introduction, or one sentence describing the specificity of the location involved in the sentence pairs. Of course, one could expect that these tasks would differentially influence the amount of source citations in the summaries. However, in alignment with the D-ISC assumption, we predicted that there would still be a main effect of story version on source recall in Experiment 2 and, importantly, that type of task would not moderate these effects.

\section{Method}

\section{Participants}

A group of 56 French undergraduate students enrolled in a psychology program participated in this experiment. All were native French speakers. The data for 1 participant were not analyzed due to a failure to adhere to the task instructions. Thus, the final sample size was 55 participants (average age 19.92 years, $S D=1.08$; $89 \%$ of the participants were female). All participants were compensated with $1 \mathrm{~h}$ of course credit for their participation.

\section{Materials}

Texts A subset of 10 critical stories from Experiment 1 was used for Experiment 2. Structurally, the consistent and discrepant versions of the stories were identical to those used in Experiment 1, save for the fact that all connectors relating the two sentences were removed. Accordingly, the Experiment 2 materials involved presentation of the sentences on two separate lines of text, and participants received a random ordering of 10 critical ( 5 discrepant and 5 consistent) and 5 filler stories. 
Because the consistent and discrepant connectors were removed, an additional pilot study was conducted to assess students' perceptions of the consistency of the present set of critical stories. A group of 16 undergraduate students who did not participate in the main study participated for course credit. They were asked to read the stories and to rate whether a story "contained a disagreement or a contradiction" on a scale from 0 (no contradiction at all) to 10 (very strong contradiction). The average ratings for the consistent and discrepant versions were $0.93(S D=1.13)$ and 8.96 $(S D=1.22)$, respectively. In only 11 of the 160 ratings $(6.9 \%)$ did participants provide a rating that was on the "wrong" side of the scale (i.e., higher than 5 for consistent versions or lower than 5 for discrepant versions). These unexpected ratings were distributed across 6 of the 10 stories and 8 of the 16 students. Importantly, these rating patterns were virtually identical to the ratings obtained with the Experiment 1 materials. In brief, students were able to clearly identify the status of each story, even without the presence of connectors.

Cued recall test Memory for the source-content links was assessed using the 10 statements taken from the second sentences of the critical stories.

\section{Procedure}

Participants were tested in small groups. They were first informed that they would read information contained within a booklet and would respond to questions based on what they read. After consent was established, readers were tasked to silently read the series of two-sentence stories and, after each story, to write a one-sentence summary, a one-sentence introduction, or one sentence specifying the location at which the story took place in the space provided. Thus, the Experiment 2 instructions were more general than those of Experiment 1, in the sense that participants were not specifically instructed to read from the perspective of an editor at a news agency on the Internet. As in Experiment 1, the instructions for all three groups specified that the readers should try to remember the story because they would be asked to recall information from the story later in the experimental session. In all other respects, the Experiment 2 procedure was identical to that of Experiment 1.

\section{Results}

Source citation in reader-generated sentences

The scoring of source citations in the Experiment 2 data was identical to the procedure used in Experiment 1. Source citations in the reader-generated sentences were submitted to ANOVA using reading task condition (summarization, introduction, or location specification) as the betweenparticipants variable and story consistency (discrepant or consistent) as the within-participants variable. For all $F_{1}$ analyses, participants were used as the random source of variance; for all $F_{2}$ analyses, items were used as the random source of variance.

Significant effects of reading task $\left[F_{1}(2,52)=20.91, p<\right.$ $\left..001, \eta_{\mathrm{p}}{ }^{2}=.45 ; F_{2}(2,27)=77.39, p<.001, \eta_{\mathrm{p}}^{2}=.85\right]$ and story version $\left[F_{1}(1,52)=28.87, p<.001, \eta_{\mathrm{p}}^{2}=.36\right.$; $\left.F_{2}(1,27)=39.82, p<.001, \eta_{\mathrm{p}}{ }^{2}=.60\right]$ were qualified by a significant interaction $\left[F_{1}(2,52)=5.91, p<.01, \eta_{\mathrm{p}}{ }^{2}=.19\right.$; $\left.F_{2}(2,27)=7.56, p<.01, \eta_{\mathrm{p}}{ }^{2}=.36\right]$. (See the left portion of Table 3 for the means and standard deviations associated with this analysis.) Regarding the simple effects, summarizers cited proportionately more sources associated with discrepant than with consistent stories $\left[F_{1}(1,52)=27.47, p<.001, \eta_{\mathrm{p}}{ }^{2}=.35\right.$; $\left.F_{2}(1,27)=34.60, p<.001, \eta_{\mathrm{p}}{ }^{2}=.56\right]$, as did introducers $\left[F_{1}(1,52)=11.79, p<.01, \eta_{\mathrm{p}}{ }^{2}=.19 ; F_{2}(1,27)=20.46, p<\right.$ $\left..001, \eta_{\mathrm{p}}^{2}=.43\right]$. However, those who were tasked to specify the location within the stories displayed low and similar levels of source citation as a function of the story version that they were reading $\left[F_{1}(1,52)<1, F_{2}(1,27)<1\right.$, both n.s.].

\section{Cued-recall test performance}

The scoring of source recall accuracy was identical to the procedure used in Experiment 1. The accuracy of source recall was submitted to ANOVA using reading task condition (summarization, introduction, or location specification) as the between-participants variable and story consistency (discrepant or consistent) as the withinparticipants variable. There were significant effects of reading task $\left[F_{1}(2,52)=4.29, p<.05, \eta_{\mathrm{p}}{ }^{2}=.14\right]$ and story version $\left[F_{1}(1,52)=4.53, p<.05, \eta_{\mathrm{p}}{ }^{2}=.08\right]$; however, the interaction did not approach significance $\left[F_{1}(2,52)<1\right.$, n.s.]. (See the right side of Table 3 for the means and standard deviations associated with this analysis.) Regarding the significant main effect for reading task, summarizers generally recalled more sources than did those specifying location $(M=2.94$ vs. 1.87 , mean difference $=$ $1.08, p<.01)$. Performance was similar for summarizers and introducers $(M=2.22)$, though the trend favored summarizers: mean difference $=0.72, p=.062$. More importantly, readers accurately recalled more sources from discrepant than from consistent stories $(M=2.56$ vs. 2.14, mean difference $=0.42, p<.05$ ). When analyzing the accuracy of source recall using items as a random source of variance, the only significant effect was for story versionagain, readers recalled more sources from discrepant than from consistent stories $\left[M=4.67\right.$ vs. $3.90 ; F_{2}(1,27)=5.58$, $\left.p<.05, \eta_{\mathrm{p}}{ }^{2}=.17\right]$. In this analysis, the reading task main 
Table 3 Experiment 2: Average source citation proportions and average source recall frequencies as a function of reading task

Descriptive statistics reflect analyses conducted using participants as the source of random variance.

\begin{tabular}{|c|c|c|c|c|}
\hline & \multicolumn{2}{|c|}{ Source Citation } & \multicolumn{2}{|c|}{ Source Recall } \\
\hline & $\begin{array}{l}\text { Discrepant } \\
\text { Mean }(S D)\end{array}$ & $\begin{array}{l}\text { Consistent } \\
\text { Mean }(S D)\end{array}$ & $\begin{array}{l}\text { Discrepant } \\
\text { Mean }(S D)\end{array}$ & $\begin{array}{l}\text { Consistent } \\
\text { Mean }(S D)\end{array}$ \\
\hline Summarization & $.70(.28)$ & $.38(.38)$ & $3.33(1.28)$ & $2.56(1.42)$ \\
\hline Introduction & $.37(.30)$ & $.16(.20)$ & $2.33(1.46)$ & $2.11(1.32)$ \\
\hline Location specification & $.10(.17)$ & $.06(.12)$ & $2.00(1.37)$ & $1.74(1.24)$ \\
\hline
\end{tabular}

effect did not reach significance $\left[F_{2}(2,27)=2.16, p=.14\right.$, $\left.\eta_{\mathrm{p}}{ }^{2}=.14\right]$, nor did the interaction approach significance $\left[F_{2}(2,27)<1\right.$, n.s. $]$.

\section{Discussion}

In Experiment 2, we found support for the generalizability of the D-ISC assumption. First, omission of the intersentential connectors did not change the overall nature of the Experiment 1 effects. That is, readers were still more likely to use source information within their gist representation statements, and also displayed better memory for information sources that were presented in conjunction with discrepant assertions, as compared to cases in which the information sources agreed. Thus, the Experiment 2 findings further supported the claim that readers' gist and memory benefits were induced by content-based discrepancies, and not the more simplistic view that the intersentential connectors accounted for these effects.

It is important to note that examination of the means across Experiments 1 and 2 might tempt one to compare average source memory across the experiments to "test" whether connectors had some added value in promoting memory for the source-content links (above and beyond the content-based discrepancy). Such direct comparisons cannot be made for several reasons. First, the Experiment 1 sessions were conducted with individual participants, whereas the Experiment 2 sessions were conducted in groups. A related issue is that there may have been demand characteristics associated with the individuals in Experiment 1, who were made aware that their eye movements were being recorded and monitored. Finally, because we were not intending to test whether the presence of connectors enhanced the source memory effects associated with discrepant stories, participants were not randomly assigned across Experiments 1 and 2. Nevertheless, the source memory effect was replicated and produced medium to large effect sizes (Cohen, 1988) across both experiments.

The Experiment 2 data were also consistent with the DISC prediction that the better memory for source-content links associated with discrepant stories would generalize to additional reading tasks. Inspection of the means in Table 3 clearly shows some gradation in memory for the sourcecontent links, depending on the reading task. However, mean inspection also highlights that all readers, regardless of reading goal, displayed memory for the information sources favoring discrepant over consistent stories. This was even the case when readers merely specified the location setting of each story, a task that presumably did not focus their attention on situational coherence. Thus, the Experiment 2 data also supported some generalization of the effects predicted by D-ISC, in that the results from Experiment 1 were not completely dependent on the task.

\section{General discussion}

The present set of experiments directly tested the D-ISC assumption that discrepancies function as a mechanism for inducing readers to construct mental representations of texts that include source-content links as organizational components. Three main findings emerged.

First, readers fixated more often and spent a longer amount of time on both information sources when the news stories presented discrepant content assertions than when they presented consistent ones (Exp. 1). Second, readers spontaneously mentioned more sources when they generated gist representations for discrepant rather than for consistent stories (Exps. 1 and 2). The type of task that readers performed in Experiment 2 moderated this effect. Tasks that presumably promoted readers' monitoring of the global consistency of information while reading (summary and introduction) appeared to produce stronger effects favoring the discrepant story conditions, as compared to a task that presumably did not (location specification). Third, readers consistently displayed better recall of the sourcecontent links from discrepant than from consistent stories. This effect was produced when connectors and content signaled the discrepancy (Exp. 1) and when only the content signaled the discrepancy (Exp. 2). In alignment with our predictions, discrepancies induced better memory for source-content links, regardless of the task-related reading goals.

The present findings are novel in providing the first empirical support for the processing and representational 
claims associated with the D-ISC assumption. The data suggest that readers readily notice breaks in situational coherence in texts. With respect to the two-sentence materials, the close proximity of the discrepant content assertions likely ensured their coactivation in working memory, a condition that van den Broek and Kendeou (2008) have previously related to the noticing of discrepant assertions in refutation texts. The data also suggest that readers selectively reprocessed the source-content links as a consequence of the presence of the discrepancy. That is, they returned to and reprocessed source areas of interest, but this happened more often and for longer periods of time if the readers had come across a discrepancy.

Readers also used the source-content links more often when they produced their gist representations of the discrepant texts (indications of what they thought were the most important features when the texts were available) and, importantly, displayed a greater presence of these sourcecontent links in their memory representations of the events (in terms of postreading recall of source information when the texts were not available). Thus, as specified in D-ISC, readers appeared to integrate information from multiple messages by attending to the respective sources of the messages during reading, which resulted in the construction of text representations that used sources as a principal organizing factor.

Globally, these effects are consistent with research demonstrating that content-based discrepancies impact readers' moment-by-moment processing and memory for texts (Albrecht \& O’Brien, 1993; Baker \& Anderson, 1982; Cook \& Myers, 2004; Hakala \& O’Brien, 1995; O'Brien \& Albrecht, 1992; O’Brien \& Myers, 1985; Rinck et al. 2003; Tapiero \& Otero, 1999). In relating our eye movement findings to the previous research on situation-based integration mechanisms, however, a few critical differences are worthy of discussion. Contrary to predictions that one might make from situation-based integration mechanisms, readers did not go back to and reprocess discrepant as compared to consistent content statements, an effect that has been well-documented in previous research (Cook \& Myers, 2004; Rayner et al. 2006; Rinck et al. 2003). In the case that different sources presented discrepant content assertions, resolution strategies instead involved going back within the text to more deeply encode the source information.

Therefore, the present work provides novel insight into the online comprehension of discrepancies in texts. Our data support the theory that, in addition to situation-based resolution strategies (e.g., generating inferences to resolve content-based discrepancies: "hedging"), readers appear to apply different resolution strategies when the discrepant content assertions can be attributed to different information sources. In returning to the fire example, a source-indexing resolution strategy appears to serve as a means by which readers are able to represent discrepant causes for a fire (sabotage vs. an electrical malfunction) by indexing each cause onto its respective information source ("the detective claims" and "the journalist asserts", respectively). Increased attention to sources in service of constructing these links may provide a means by which readers extract relevant cues that explain why a certain source is providing a certain account of the situation, whereas another source provides an altogether different account of the same situation. In this sense, readers may rely on information sources as one mechanism for integrating disparate pieces of information into a coherent mental representation of a text.

Moreover, it is noteworthy that the empirical findings in the present work cannot be completely explained by dominant theories of source memory (e.g., the sourcemonitoring framework; M.K. Johnson et al. 1993) that characterize readers' memories of sources as being based on decisions made about the features of their memory representations after reading. We interpret that the pairing of "deeper" encoding of source-content links during reading with better memory for source-content links after reading is uniquely described by the D-ISC assumption examined in the present work. Thus, it appears that, in certain situations, people do specifically mark events according to their sources during encoding, which benefits subsequent memory for this information after some delay.

Consequently, the present work has the implication that tagging will occur specifically when readers attempt to comprehend situations in which the sources have meaning and are functionally operational, as a way to resolve discrepancies. That is to say, the present work does not presuppose that readers always construct mental representations using source-content links under any kind of reading circumstances. We speculate that situations that promote consideration of the motives, goals, or knowledge of information sources, in particular, may help readers resolve discrepancies in terms of indexing each discrepant account onto its respective source in their memory representation of the text. We expect that when the sources are not meaningful or distinctive (e.g., Kim \& Millis, 2006), readers may not find them useful for resolving a discrepancy. In contrast, highly elaborated sources (e.g., the detective-who is an expert consultant for potential sabotage cases) may lead to even greater elaborations with the content (e.g., the detective may be more knowledgeable concerning indications of sabotage, which may explain the conflicting accounts of the situation).

Our empirical findings also add to the understanding of research based on the comprehension of multiple distinct documents (Britt et al. 1999; Rouet, Britt, Mason, \& Perfetti, 1996; Stadtler et al., 2011; Strømsø et al., 2010; Wiley et al., 2009). Researchers with this focus have found evidence suggesting that "good" comprehension of multiple 
conflicting documents involves a greater consideration of their source features. However, the designs of none of these experiments have manipulated the presence of discrepancies per se. Moreover, empirical evidence to date has demonstrated a relationship between comprehension and source consideration and evaluation in terms of the "products" of reading (i.e., indications of postreading understandings of multiple documents). To give an example, Strømsø et al. (2010) demonstrated that performance on a source memory test significantly predicted performance on an inference verification test, which both measured aspects of text representations after the reading process had been completed. The present work further indicates that discrepancies between multiple messages appear to promote readers' strategic attention to and evaluation of source information during encoding. Readers noticed discrepancies as they occurred and responded by constructing mental representations of the texts in which source-content links were central to the organization ("deeper" source encoding was unique to rereading). Thus, the D-ISC findings in the present work support previous empirical research on multiple-document comprehension by identifying that readers do indeed evaluate information sources during comprehension situations in which multiple conflicting accounts are based on different arguments or assertions. The present work not only extends research on the comprehension of document sources to sources embedded within a document, but also provides a process by which one can interpret the previous empirical support for postreading relationships between good comprehension and source consideration and evaluation.

Future research efforts should investigate whether the DISC assumptions extend to reading contexts involving longer texts. In extended discourse, discrepant assertions may be situated much farther away from each other, with several sentences, paragraphs, or even complete texts potentially unfolding between them. We postulate that associative or resonance processes would likely reactivate the discrepant content assertion from long-term memory (presumably influenced by the degree of content overlap in the assertions), instigating noticing and reconciliation processes in service of reestablishing coherence. Much previous research has validated that resonance-like processes function to reactivate discrepant content information in extended discourse, although sources were not mentioned in these comprehension contexts (Albrecht \& O'Brien, 1993; Myers \& O’Brien, 1998; O’Brien \& Myers, 1985, 1999; O’Brien et al., 1998). As such, test extensions of the D-ISC processing assumption should incorporate longer texts, to ensure that the first content assertion is no longer activated in working memory. Several tractable questions could arise from extensions in this vein. Do readers reactivate discrepant content assertions and notice discrep- ancies when the assertions are embedded within longer news stories? Does the degree of content overlap in the discrepant assertions influence the likelihood that readers will notice and attempt to reconcile the discrepancy? Do readers increase their attention to sources after having come across the discrepancy, rather than going back to and reprocessing discrepant content information?

Future research efforts should also investigate whether the D-ISC assumptions extend to reading contexts involving clearly demarcated documents. It is an open empirical question whether and in what ways document boundariespotentially signifying distinct entities - might enhance the effects presented in our work. Empirical work in this vein could serve as a more direct test of whether conflicting accounts of a single situation presented in multiple distinct documents might also induce a deeper consideration of source features during reading. If we assume that discrepancies are frequently presented by multiple sources within everyday comprehension contexts, it will be of interest for researchers to further specify the complex ways that text features, reader characteristics, and reading purposes (e.g., for pleasure vs. to complete a school assignment) interact to affect processing, representation, and longer-term memory for texts.

Author note The authors thank Marie-Françoise Crété, Julien Dampuré, and Dominique Knutsen for their help in conducting the experimental sessions or in coding responses. The authors also thank Edward J. O'Brien and two anonymous reviewers for their helpful comments on a previous version of the manuscript. This article was funded in part by a University of Poitiers visiting researcher grant to $\mathrm{J}$. L.G.B., Grant ANR-08-COMM-011-01 from the Agence Nationale de la Recherche (French National Research Agency) to the Center for Research on Cognition and Learning, and a grant from the Région Poitou-Charentes to M.A.B. Any opinions, findings, conclusions, or recommendations expressed in this material are those of the author(s) and do not necessarily reflect the views of these institutions.

\section{References}

Albrecht, J. E., \& O’Brien, E. J. (1993). Updating a mental model: Maintaining both local and global coherence. Journal of Experimental Psychology: Learning, Memory, and Cognition, 19, 1061-1070. doi:10.1037/0278-7393.19.5.1061

Anmarkrud, Ø., Bråten, I., \& Strømsø, H. I. (2011). Constructively responsive comprehension strategies during multiple-text reading: A think-aloud study. New Orleans, LA: Paper presented at the annual meeting of the American Educational Research Association, April.

Baker, L., \& Anderson, R. I. (1982). Effects of inconsistent information on text processing: Evidence for comprehension monitoring. Reading Research Quarterly, 17, 281-294. doi:10.2307/747487

Black, J. B., Turner, T. J., \& Bower, G. H. (1979). Point of view in narrative comprehension, memory, and production. Journal of Verbal Learning and Verbal Behavior, 18, 187-198. doi:10.1016/ S0022-5371(79)90118-X 
Blanc, N., Kendeou, P., van den Broek, P., \& Brouillet, D. (2008). Updating situation models during reading of news reports: Evidence from empirical data and simulations. Discourse Processes, 45, 103-121. doi:10.1080/01638530701792784

Blanchard, H. E., \& Iran-Nejad, A. (1987). Comprehension processes and eye movement patterns in the reading of surprise-ending stories. Discourse Processes, 10, 127-138. doi:10.1080/ 01638538709544663

Britt, M. A., Perfetti, C. A., Sandak, R., \& Rouet, J. F. (1999). Content integration and source separation in learning from multiple texts. In S. R. Goldman, A. C. Graesser, \& P. van den Broek (Eds.), Narrative comprehension, causality, and coherence: Essays in honor of Tom Trabasso (pp. 209-233). Mahwah, NJ: Erlbaum.

Caron, J., Micko, H. C., \& Thüring, M. (1988). Conjunctions and the recall of composite sentences. Journal of Memory and Language, 27, 309-323. doi:10.1016/0749-596X(88)90057-5

Chinn, C. A., \& Brewer, W. F. (1993). The role of anomalous data in knowledge acquisition: A theoretical framework and implications for science instruction. Review of Educational Research, 63, 149.

Chinn, C. A., \& Brewer, W. F. (1998). An empirical test of a taxonomy of responses to anomalous data in science. Journal of Research in Science Teaching, 35, 623-654. doi:10.1002/(SICI) 1098-2736(199808)35:6<623::AID-TEA3>3.0.CO;2-O

Cohen, J. (1988). Statistical power analysis for the behavioral sciences (2nd ed.). Hillsdale, NJ: Erlbaum.

Cook, A. E., Halleran, J. G., \& O'Brien, E. J. (1998). What is readily available during reading? A memory-based view of text processing. Discourse Processes, 26, 109-129. doi:10.1080/01638539809545041

Cook, A. E., \& Myers, J. L. (2004). Processing discourse roles in scripted narratives: The influences of context and world knowledge. Journal of Memory and Language, 50, 268-288. doi:10.1016/j.jml.2003.11.003

Daneman, M., Lennertz, T., \& Hannon, B. (2007). Shallow semantic processing of text: Evidence from eye movements. Language \& Cognitive Processes, 22, 83-105. doi:10.1080/ 01690960500372725

Frazier, L., \& Rayner, K. (1982). Making and correcting errors during sentence comprehension: Eye movements in the analysis of structurally ambiguous sentences. Cognitive Psychology, 14, 178-210. doi:10.1016/0010-0285(82)90008-1

Gernsbacher, M. A., Goldsmith, H. H., \& Robertson, R. R. W. (1992). Do readers mentally represent characters' emotional states? Cognition and Emotion, 6, 89-111. doi:10.1080/ 02699939208411061

Gerrig, R. J., \& O'Brien, E. J. (2005). The scope of memory-based processing. Discourse Processes, 39(2\&3), 225-242.

Goldman, S., Braasch, J. L. G., Wiley, J., Gepstein, R., Brodowinska, K., \& Graesser, A. C. (2004). Doing research on the Web: Comprehending complex science information. Chicago, IL: Paper presented at the annual meeting of the Society for Text and Discourse.

Goldman, S. R., Golden, R. M., \& van den Broek, P. (2007). Why are computational models of text comprehension useful? In C. A. Perfetti \& F. Schmalhofer (Eds.), Higher-level language processes in the brain: Inference and comprehension processes (pp. 27-51). Mahwah, NJ: Erlbaum.

Goldman, S. R., \& Varma, S. (1995). CAPing the constructionintegration model of discourse comprehension. In C. A. Weaver III, S. Mannes, \& C. R. Fletcher (Eds.), Discourse comprehension: Essays in honor of Walter Kintsch (pp. 337-358). Hillsdale, NJ: Erlbaum.

Goldman, S. R., Varma, S., \& Coté, N. (1996). Extending capacityconstrained construction integration: Toward "smarter" and flexible models of text comprehension. In B. K. Britton \& A.
C. Graesser (Eds.), Models of understanding text (pp. 73-113). Hillsdale, NJ: Erlbaum.

Guéraud, S., Harmon, M. E., \& Peracchi, K. A. (2005). Updating situation models: The memory-based contribution. Discourse Processes, 39, 243-263.

Hakala, C. M., \& O'Brien, E. J. (1995). Strategies for resolving coherence breaks in reading. Discourse Processes, 20, 167-185. doi:10.1080/01638539509544936

Hyönä, J., Lorch, R. F., Jr., \& Rinck, M. (2003). Eye movement measures to study global text processing. In J. Hyönä, R. Radach, \& H. Deubel (Eds.), The mind's eye: Cognitive and applied aspect of eye movement research (pp. 313-334). Amsterdam, The Netherlands: Elsevier Science BV.

Johnson, H. M., \& Seifert, C. M. (1994). Sources of the continued influence effect: When misinformation in memory affects later inferences. Journal of Experimental Psychology: Learning, Memory, and Cognition, 20, 1420-1436. doi:10.1037/02787393.20.6.1420

Johnson, H. M., \& Seifert, C. M. (1998). Updating accounts following a correction of misinformation. Journal of Experimental Psychology: Learning, Memory, and Cognition, 24, 1483-1494. doi:10.1037/0278-7393.24.6.1483

Johnson, H. M., \& Seifert, C. M. (1999). Modifying mental representations: Comprehending corrections. In H. van Oostendorp \& S. R. Goldman (Eds.), The construction of mental representations during reading (pp. 303-318). Mahwah, NJ: Erlbaum.

Johnson, M. K., Hashtroudi, S., \& Lindsay, D. S. (1993). Source monitoring. Psychological Bulletin, 114, 3-28. doi:10.1037/ 0033-2909.114.1.3

Kim, H.-J. J., \& Millis, K. (2006). The influence of sourcing and relatedness on event integration. Discourse Processes, 41, 51-65. doi:10.1207/s15326950dp4101_4

Kintsch, W. (1988). The role of knowledge in discourse comprehension: A construction-integration model. Psychological Review, 95, 163-182. doi:10.1037/0033-295X.95.2.163

Kintsch, W. (1998). Comprehension: A paradigm for cognition. New York: Cambridge University Press.

Likert, R., \& Quasha, W. (1995). Revised Minnesota Paper Form Board Test manual (2nd ed.). San Antonio, TX: Psychological Corp.

McKoon, G., \& Ratcliff, R. (1992). Inference during reading. Psychological Review, 99, 440-466. doi:10.1037/0033295X.99.3.440

Millis, K. K., \& Just, M. A. (1994). The influence of connectives on sentence comprehension. Journal of Memory and Language, 33, 128-147. doi:10.1006/jmla.1994.1007

Mosenthal, P. (1979). Children's strategy preferences for resolving contradictory story information under two social conditions. Journal of Experimental Child Psychology, 28, 323-343.

Myers, J. L., \& O'Brien, E. J. (1998). Accessing the discourse representation during reading. Discourse Processes, 26, 131-157. doi: 10.1080/01638539809545042

Myers, J. L., O’Brien, E. J., Albrecht, J. E., \& Mason, R. A. (1994). Maintaining global coherence during reading. Journal of Experimental Psychology: Learning, Memory, and Cognition, 20, 876886. doi:10.1037/0278-7393.20.4.876

Noordman, L. G. M., \& Vonk, W. (1997). The different functions of a conjunction in constructing a representation of the discourse. In J. Costermans \& M. Fayol (Eds.), Processing interclausal relationships: Studies in the production and comprehension of text (pp. 75-93). Mahwah, NJ: Erlbaum.

O’Brien, E. J., \& Albrecht, J. E. (1992). Comprehension strategies in the development of a mental model. Journal of Experimental Psychology: Learning, Memory, and Cognition, 18, 777-784. doi: $10.1037 / 0278-7393.18 .4 .777$

O’Brien, E. J., \& Myers, J. L. (1985). When comprehension difficulty improves memory for text. Journal of Experimental Psychology: 
Learning, Memory, and Cognition, 11, 12-21. doi:10.1037/02787393.11.1.12

O’Brien, E. J., \& Myers, J. L. (1999). Text comprehension: A view from the bottom up. In S. R. Goldman, A. C. Graesser, \& P. van den Broek (Eds.), Narrative comprehension, causality, and coherence: Essays in honor of Tom Trabasso (pp. 35-53). Mahwah, NJ: Erlbaum.

O’Brien, E. J., Rizzella, M. L., Albrecht, J. E., \& Halleran, J. G. (1998). Updating a situation model: A memory-based text processing view. Journal of Experimental Psychology: Learning, Memory, and Cognition, 24, 1200-1210. doi:10.1037/02787393.24.5.1200

Otero, J., \& Kintsch, W. (1992). Failures to detect contradictions in text: What readers believe versus what they read. Psychological Science, 3, 229-235.

Perfetti, C. A., Rouet, J.-F., \& Britt, M. A. (1999). Towards a theory of documents representation. In $\mathrm{H}$. van Oostendorp \& S. R. Goldman (Eds.), The construction of mental representations during reading (pp. 99-122). Mahwah, NJ: Erlbaum.

Rapp, D. N., Gerrig, R. J., \& Prentice, D. A. (2001). Readers' traitbased models of characters in narrative comprehension. Journal of Memory and Language, 45, 737-750.

Rapp, D. N., \& Kendeou, P. (2007). Revising what readers know: Updating text representations during narrative comprehension. Memory \& Cognition, 35, 2019-2032. doi:10.3758/BF03192934

Rapp, D. N., \& Kendeou, P. (2009). Noticing and revising discrepancies as texts unfold. Discourse Processes, 46, 1-24. doi:10.1080/01638530802629141

Rayner, K. (1998). Eye movements in reading and information processing: 20 years of research. Psychological Bulletin, 124, 372-422. doi:10.1037/0033-2909.124.3.372

Rayner, K., Chace, K. H., Slattery, T. J., \& Ashby, J. (2006). Eye movements as reflections of comprehension processes in reading. Scientific Studies of Reading, 10, 214-255. doi:10.1207/ s1532799xssr1003_3

Rinck, M., Gámez, E., Díaz, J. M., \& de Vega, M. (2003). Processing of temporal information: Evidence from eye movements. Memory \& Cognition, 31, 77-86. doi:10.3758/BF03196084

Rinck, M., Hähnel, A., \& Becker, G. (2001). Using temporal information to construct, update, and retrieve situation models of narratives. Journal of Experimental Psychology: Learning, Memory, and Cognition, 27, 67-80.

Rouet, J.-F. (2006). The skills of document use: From text comprehension to Web-based learning. Mahwah, NJ: Erlbaum.

Rouet, J.-F., Britt, M. A., Caroux, L., Nivet, C., \& Le Bigot, L. (2009, month). When do readers construct document models? The role of source information and story consistency. Paper presented at the biennial meeting for the European Association for Research on Learning and Instruction, August.

Rouet, J.-F., Britt, M. A., Mason, R. A., \& Perfetti, C. A. (1996). Using multiple sources of evidence to reason about history. Journal of Educational Psychology, 88, 478-493.

Sanders, T. J. M., \& Noordman, L. G. M. (2000). The role of coherence relations and their linguistic markers in text processing. Discourse Processes, 29, 37-60. doi:10.1207/S15326950dp2901_3

Seifert, C. M. (2002). The continued influence of misinformation in memory: What makes a correction effective? In B. H. Ross (Ed.), The psychology of learning and motivation: Advances in research and theory (Vol. 41, pp. 265-292). San Diego, CA: Academic Press.

Stadtler, M., Scharrer, L., Brummenhenrich, B., \& Bromme R. (2011). Dealing with the uncertain: How readers detect and attribute conflicts in science texts as a function of discourse expectations. Manuscript submitted for publication.
Stewart, A. J., Pickering, M. J., \& Sturt, P. (2004). Using eye movements during reading as an implicit measure of acceptability of brand extensions. Applied Cognitive Psychology, 18, 697-709.

Strømsø, H. I., Bråten, I., \& Britt, M. A. (2010). Reading multiple texts about climate change: The relationship between memory for sources and text comprehension. Learning and Instruction, 20, 192-204

Tapiero, I., \& Otero, J. (1999). Distinguishing between textbase and situation model in the processing of inconsistent information. In H. van Oostendorp \& S. R. Goldman (Eds.), The construction of mental representations during reading (pp. 341-365). Mahwah, NJ: Erlbaum.

van den Broek, P., \& Kendeou, P. (2008). Cognitive processes in comprehension of science texts: The role of co-activation in confronting misconceptions. Applied Cognitive Psychology, 22, 335-351. doi:10.1002/acp.1418

van den Broek, P., Rapp, D. N., \& Kendeou, P. (2005). Integrating memory-based and constructionist processes in accounts of reading comprehension. Discourse Processes, 39, 299-316. doi:10.1207/s15326950dp3902\&3 11

van den Broek, P., Risden, K., \& Husebye-Hartmann, E. (1995). The role of readers' standards for coherence in the generation of inferences during reading. In R. F. Lorch Jr. \& E. J. O'Brien (Eds.), Sources of coherence in reading (pp. 353-373). Hillsdale, NJ: Erlbaum.

van den Broek, P., \& Trabasso, T. (1986). Causal networks versus goal hierarchies in summarizing text. Discourse Processes, 9, 1-15. doi:10.1080/01638538609544628

van den Broek, P., Young, M., Tzeng, Y., \& Linderholm, T. (1999). The Landscape model of reading: Inferences and the online construction of memory representation. In H. van Oostendorp \& S. R. Goldman (Eds.), The construction of mental representations during reading (pp. 71-98). Mahwah, NJ: Erlbaum.

van Oostendorp, H. (2002). Updating mental representations during reading science text. In J. Otero, J. A. Leon, \& A. C. Graesser (Eds.), The psychology of science text comprehension (pp. 309329). Mahwah, NJ: Erlbaum.

van Oostendorp, H., \& Bonebakker, C. (1999). Difficulties in updating mental representations during reading news reports. In H. van Oostendorp \& S. R. Goldman (Eds.), The construction of mental representations during reading (pp. 319-339). Mahwah, NJ: Erlbaum.

Vauras, M., Hyönä, J., \& Niemi, P. (1992). Comprehending coherent and incoherent texts: Evidence from eye movement patterns and recall performance. Journal of Research in Reading, 15, 39-54.

Wiley, J., Goldman, S. R., Graesser, A. C., Sanchez, C. A., Ash, I. K., \& Hemmerich, J. A. (2009). Source evaluation, comprehension, and learning in Internet science inquiry tasks. American Educational Research Journal, 46, 1060-1106.

Wiley, J., \& Rayner, K. (2000). Effects of titles on the processing of text and lexically ambiguous words: Evidence from eye movements. Memory \& Cognition, 28, 1011-1021.

Wilkes, A. L., \& Leatherbarrow, M. (1988). Editing episodic memory following the identification of error. Quarterly Journal of Experimental Psychology, 40A, 361-387. doi:10.1080/ 02724988843000168

Wineburg, S. S. (1991). Historical problem solving: A study of the cognitive processes used in the evaluation of documentary and pictorial evidence. Journal of Educational Psychology, 83, 7387.

Zwaan, R. A., \& Madden, C. J. (2004). Updating situation models. Journal of Experimental Psychology: Learning, Memory, and Cognition, 30, 283-288. doi:10.1037/0278-7393.30.1.283 